\title{
Mitteilungen der ACP
}

coloproctology $2012 \cdot 34: 320$

DOI 10.1007/s00053-012-0308-2

() Springer-Verlag 2012

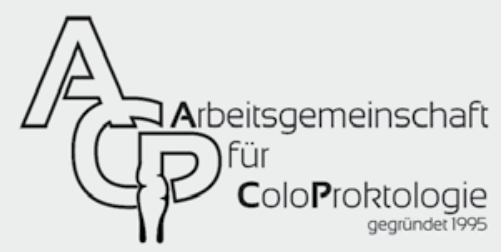

\section{Korrespondenzadresse}

Arbeitsgemeinschaft für Coloproktologie (ACP)

der Österreichischen Gesellschaft für Chirurgie

Sekretariat Dr. Irmgard Kronberger

Univ.-Klinik für Visceral-, Transplantations- und Thoraxchirurgie,

Medizinische Universität Innsbruck

Anichstrasse 35, A-6020 Innsbruck

Tel.: +43/(0)512 504-0

E-Mail: irmgard.kronberger@i-med.ac.at

www.coloproctology.info

\section{Innsbrucker Coloproktologie Wintertagung}

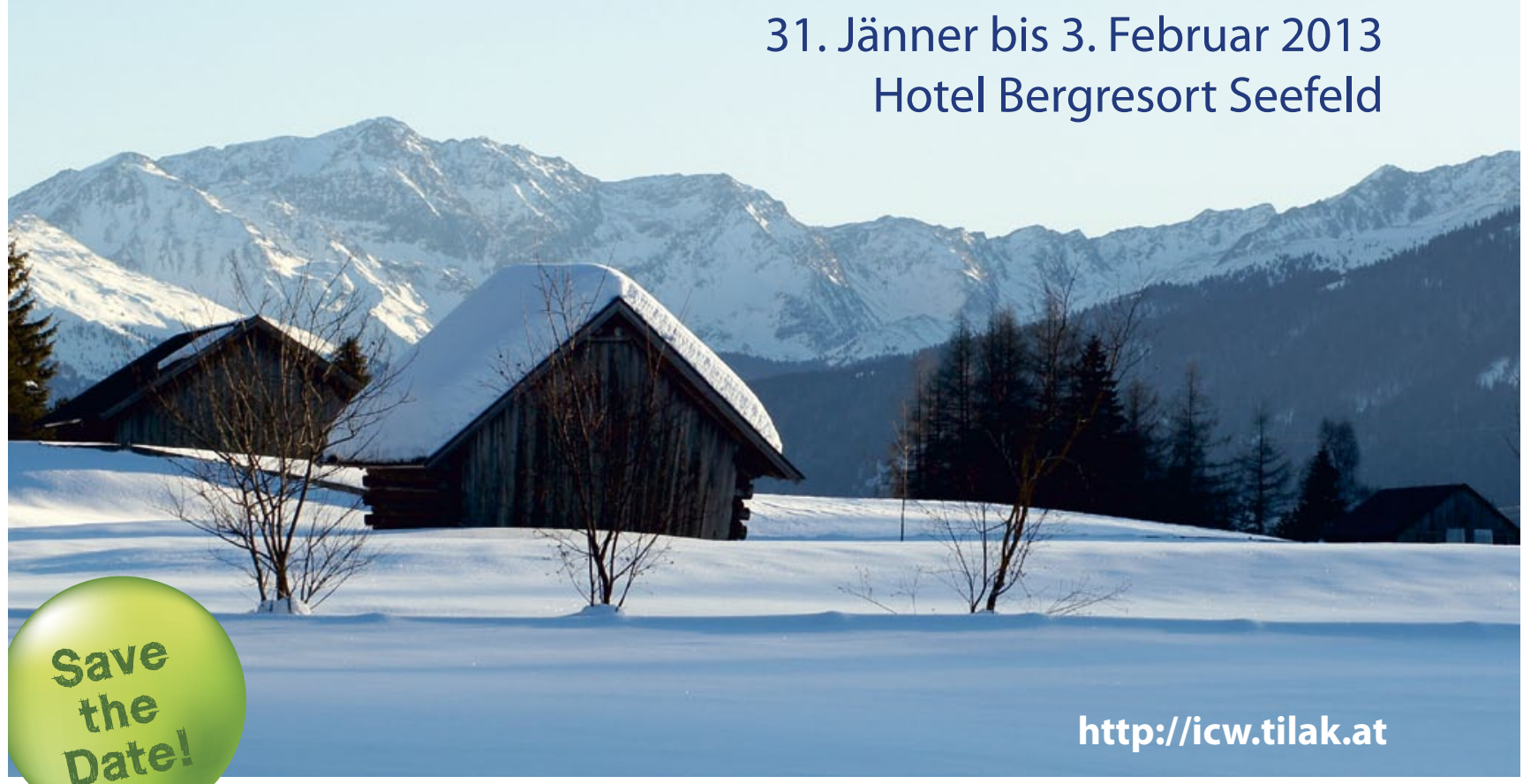

Die Universitätsklinik für Visceral-, Transplantations- und Thoraxchirurgie Innsbruck veranstaltet im nächsten Jahr in Zusammenarbeit mit der Arbeitsgemeinschaft für Coloproktologie (ACP) die mittlerweile 6. Innsbrucker Coloproktologie Wintertagung im Hotel Bergresort Seefeld von 31.1. bis 3.2.2013.

Ziel der Tagung ist es auch diesmal wieder, die Koloproktologen der deutschsprachigen Alpenländer näher zusammenzubringen und ein Forum für einen intensiven Gedankenaustausch zu den Hauptthemen "Chronisch entzündliche Darmerkrankungen", "Innovationen in der Coloproktologie" sowie „Rektumkarzinom“ zu schaffen.

Bitte tragen Sie sich schon jetzt den Termin ein, a.o. Univ.-Prof. Dr. Felix Aigner

\section{Hauptthemen*}

- Chronisch entzündliche Darmerkrankungen

- Innovationen in der Coloproktologie

- Rektumkarzinom

Veranstalter: Univ.-Klinik für Visceral-, Transplantationsund Thoraxchirurgie,

Medizinische Universität Innsbruck

Kongressorganisation: a.o. Univ.-Prof. Dr. Felix Aigner felix.aigner@i-med.ac.at Mag. (FH) Linda Partl linda.partl@uki.at 